\title{
Low prevalence of collateral cerebral circulation in the circle of Willis in patients with severe carotid artery stenosis and recent ischemic stroke
}

\author{
Rafał Badacz ${ }^{1}$, Tadeusz Przewłocki ${ }^{1,2}$, Izabela Karch ${ }^{1}$, Piotr Pieniążek ${ }^{1,2}$, Agnieszka Rosławiecka ${ }^{1}$, \\ Szymon Mleczko ${ }^{1}$, Andrzej Brzychczy ${ }^{3}$, Mariusz Trystuła ${ }^{3}$, Krzysztof Żmudka ${ }^{1}$, Anna Kabłak-Ziembicka ${ }^{1}$ \\ ${ }^{1}$ Department of Interventional Cardiology, Institute of Cardiology, Jagiellonian University School of Medicine, John Paul II Hospital, Krakow, \\ Poland \\ 2Department of Cardiac and Vascular Diseases, Institute of Cardiology, Jagiellonian University School of Medicine, John Paul II Hospital, \\ Krakow, Poland \\ ${ }^{3}$ Department of Vascular and Endovascular Surgery, John Paul II Hospital, Krakow, Poland
}

Postep Kardiol Inter 2015; 11, 4 (42): 312-317

DOI: $10.5114 /$ pwki.2015.55602

\begin{abstract}
A bstract
Introduction: The circle of Willis is thought to play a key role in development of collateral flow in patients with internal carotid artery stenosis (ICAS).

Aim: To assess flow in the circle of Willis in patients with recent ischemic stroke (IS).

Material and methods: The study included 371 patients, 102 symptomatic with severe ICAS and recent IS (within the last 3 months) (group I) and 269 asymptomatic with severe ICAS (group II). Flow in the middle (MCA), anterior (ACA) and posterior (PCA) cerebral arteries and pattern of the cross-flow through anterior (ACOA) and posterior (PCOA) communicating arteries were assessed with transcranial color-coded Doppler ultrasonography (TCCD).

Results: The ACoA or PCoA was less prevalent in group I than in group II ( $54 \%$ vs. $78 \%, p<0.001$ and $20 \%$ vs. $42 \%, p<0.001$, respectively), resulting in lower peak-systolic velocity (PSV) in the MCA in group I vs. group II $(p=0.015)$. Any collateral pathway was present in $67 \%$ of patients in group I, compared to $86 \%$ in group II $(p<0.001)$. Both PSV and end-diastolic (EDV) flow velocity in the ACA were lower in patients with recent IS, compared to asymptomatic subjects $(71 \pm 24 \mathrm{~cm} / \mathrm{s} \mathrm{vs.} 86 \pm 34 \mathrm{~cm} / \mathrm{s}, p<0.001$ and $32 \pm 12 \mathrm{~cm} / \mathrm{s}$ vs. $37 \pm 17 \mathrm{~cm} / \mathrm{s}, p=0.038$, respectively). Presence of ACoA or PCoA and higher PSV in the MCA and ACA were associated with significant risk reduction of $\mathrm{IS}(\mathrm{RR}=0.28(95 \% \mathrm{Cl}=0.16-0.49, p<0.001), \mathrm{RR}=0.28(95 \% \mathrm{Cl}=0.15-0.52, p<0.001)$, $\mathrm{RR}=0.97(95 \% \mathrm{Cl}=0.96-0.99, p<0.001), \mathrm{RR}=0.99(95 \% \mathrm{Cl}=0.98-0.99, p<0.032)$, respectively). However, ROC curves failed to show reliable MCA or ACA PSV cut-offs for IS risk assessment.
\end{abstract}

Conclusions: The ACOA and PCoA seem to play a key role in the evaluation of IS risk in subjects with severe ICAS

Key words: stroke, circle of Willis, collateral circulation, transcranial Doppler, carotid artery stenosis.

\section{Introduction}

Atherosclerotic lesions situated in extracranial arteries contribute to $10-20 \%$ of all ischemic strokes (IS) [1]. Only $20 \%$ of all IS are preceded by prodromal neurological symptoms, e.g. amaurosis fugax, transient paresthesia, limb weakness, tingling and aphasia known as transient ischemic attacks (TIA). Ischemic strokes can develop in two ways: either when diminished cerebral blood flow occurring in severe stenosis of the extracranial artery causes hypoperfusion of brain structures [2-4]; or when a cerebral artery is occluded by emboli released from the usually ulcerated, thrombogenic plaque, irrespectively of the actual grade of stenosis $[5,6]$. Both pathological mechanisms might also occur concurrently.

\section{Aim}

Our working hypothesis is that intracranial circulation is subject to variance in patients with severe internal carotid artery stenosis (ICAS). Thus, the ability to develop collateral cerebral circulation can prevent an ischemic cerebral event. The present study was there-

\section{Corresponding author:}

Rafał Badacz, Department of Interventional Cardiology, Institute of Cardiology, Jagiellonian University School of Medicine, John Paul II Hospital, 80 Prądnicka St, 31-202 Krakow, Poland, phone: +48 602123 026, e-mail: rbadacz@gmail.com Received: 15.07.2015, accepted: 30.08.2015. 
fore designed to assess hemodynamic changes and autoregulation mechanisms occurring in intracranial circulation within the circle of Willis, caused by severe ICAS in patients without neurological symptoms and those with a history of recent IS.

\section{Material and methods}

The study comprised 371 consecutive patients (265; $71 \%$ men) with ICAS $\geq 70 \%$, at mean age $66 \pm 9.0$ (44-91) years, enrolled in the study prior to carotid artery revascularization between December 2011 and April 2015, in whom diagnostic transcranial color-coded duplex ultrasound (TCCD) was performed.

The inclusion criteria were as follows: severe ICAS over $70 \%$ and diagnostic temporal window for the TCCD examination.

For the present study, cerebral and extracranial angiography was used as the standard of reference. The grade of stenosis of ICA, as well as the status of extracranial and cerebral arteries, was angiographically established in all patients. In all cases the grade of carotid stenosis measured with ultrasound differed by no more than $10 \%$, as compared to the angiographic measurement using the North American Symptomatic Carotid Endarterectomy Trial (NASCET) method [7]. The pattern of cerebral flow was also angiographically confirmed.

Study participants were divided into 2 groups depending on their symptoms and previous history of IS. The time period from IS to TCCD evaluation was determined in all subjects.

Group I consisted of 102 (27\%) subjects, including 70 (69\%) males, at the mean age of $67.6 \pm 9.5$ years, with ICAS $\geq 70 \%$ of carotid lumen reduction and with a medical history of a cerebrovascular ischemic event (stroke or TIA) within the last 3 months.

Group 2 consisted of 269 (73\%) patients, including 195 (72\%) males, at the mean age of $66.0 \pm 8.9$ years, with asymptomatic ICAS > 70\% (93 patients) or with a history of IS later than 3 months prior to TCCD assessment (176 patients).

Each patient signed an informed consent form before the revascularization procedure for ICAS. The study received the acceptance of the Jagiellonian University Bioethics Committee and was performed in accordance with the Declaration of Helsinki.

At baseline age, gender, cardiovascular risk factors (such as presence of hypertension (HT), diabetes (DM), hyperlipidemia or smoking habit), prevalence of coronary artery disease, and myocardial infarction were assessed. Blood samples were taken to assess creatinine level and lipid profile.

The history of IS of TIA was sourced from available medical documentation, and brain imaging was performed either with computed tomography (CT) or magnetic resonance imaging (MRI), together with thorough neurological examination.
The exclusion criteria were: patients with occluded ICA, non-diagnostic transtemporal TCCD approach and those who did not agree to sign an informed consent form.

Baseline characteristics of study participants, divided into study groups, are shown in Table I.

High-resolution B-Mode, color Doppler and pulse Doppler ultrasonography of extracranial arteries preceded transcranial examination and was performed with an ultrasound machine (Toshiba Aplio TUS-A300; Saronno, Italy) fitted with a linear-array $7.5 \mathrm{MHz}$ transducer. Patients from both groups were examined in a supine position with the head tilted backwards. In compliance with the Carpenter criteria the grade of stenosis in carotid arteries was assessed through measuring the increases in the peak systolic (PSV) $>2.1 \mathrm{~m} / \mathrm{s}$ and the end-diastolic $(E D V)>0.7 \mathrm{~m} / \mathrm{s}$ velocity [8]

Whenever Doppler ultrasound indicated severe ICAS, TCCD examination of intracranial arteries was performed with a Toshiba Aplio machine fitted with a sector-array 1.5-2.5 MHz transducer. The TCCD examination included measurements of PSV and EDV in the first segments of cerebral arteries within the circle of Willis: ipsilaterally to the stenosed ICA - in ipsilateral middle (MCA), anterior (ACA) and posterior (PCA) cerebral arteries.

Furthermore, the flow directions and functions of anterior ( $\mathrm{ACOA}$ ) and posterior ( $\mathrm{PCOA})$ communicating arteries were assessed. The ACoA was assessed as present when the same flow directions in the ipsilateral MCA and ACA were observed. The PCoA was assessed as present when the blood flow between the trifurcation and ipsilateral PCA (P1/P2 segment) was recorded on TCCD.

All scans were obtained by two experienced sonographers who had no prior knowledge of the subjects' clinical and angiographic characteristics.

Table I. Clinical characteristics of respective groups (calculated from Student's $t$-test and $\chi^{2}$ test)

\begin{tabular}{lccc} 
Parameter & $\begin{array}{c}\text { Group I } \\
(N=102)\end{array}$ & $\begin{array}{c}\text { Group II } \\
(N=269)\end{array}$ & $\begin{array}{c}\text { Value of } p \\
(95 \% \mathrm{CI})\end{array}$ \\
\hline Age & $67.6 \pm 9.5$ & $66.0 \pm 8.9$ & 0.050 \\
\hline Male gender & $70(69 \%)$ & $195(72 \%)$ & 0.460 \\
\hline HT & $96(94 \%)$ & $250(93 \%)$ & 0.685 \\
\hline DM & $32(31 \%)$ & $93(35 \%)$ & 0.560 \\
\hline Hyperlipidemia & $84(82 \%)$ & $246(91 \%)$ & 0.125 \\
\hline Cigarette smoking & $65(64 \%)$ & $198(74 \%)$ & 0.061 \\
\hline Ischemic heart disease* & $55(54 \%)$ & $162(60 \%)$ & 0.271 \\
\hline Myocardial infarction & $19(19 \%)$ & $93(35 \%)$ & 0.003 \\
\hline Grade of ICAS** & $85 \pm 9.6 \%$ & $83 \pm 9.4 \%$ & 0.089
\end{tabular}

*Significant coronary artery stenosis exceeding 50\% lumen reduction on coronary angiography, ${ }^{* *}$ according to NASCET criteria [7]. 


\section{Statistical analysis}

Continuous variables are presented as mean \pm SD, and categorical variables are expressed as frequencies and percentages. Means of analyzed parameters across groups were tested with the analysis of variance (ANOVA) test, and frequencies were compared by the $\chi^{2}$ test for independence. The non-parametric Mann-Whitney U test was used to determine differences in peak-systolic flow velocities recorded in the corresponding cerebral arteries among all studied groups.

The $\chi^{2}$ test was applied to assess the relationship between the grade of ICA stenosis, neurological status of patients and presence of ACOA and PCOA.

The potential factors that may be associated with higher risk of an ischemic event were identified first with the univariate analysis (ANOVA), then the multivariate one-step backward logistic regression was performed in order to determine predictors of IS. The independent variables that entered the model were those parameters which achieved a $p$-value less than 0.100 in the univariate analysis.

The sensitivity and specificity were calculated to determine the discriminating power of flow velocity in cerebral arteries by receiver-operator characteristic (ROC) curves. The area under the curve (AUC), odds ratio (OR) and confidence intervals $(\mathrm{Cl})$ were calculated for these cut-off points.

Statistical analyses were performed with Statistica 12.0 software. Statistical significance was assumed at $p<0.05$.

\section{Results}

There were no statistically significant differences regarding the majority of atherosclerosis risk factors and

Table II. Peak systolic (PSV) and end-diastolic (EDV) flow velocities in ipsilateral MCA, ACA, and PCA in neurologically symptomatic patients (group I) vs. asymptomatic patients (group II)

\begin{tabular}{lccc} 
Velocity $[\mathrm{cm} / \mathrm{s}]$ & $\begin{array}{c}\text { Group I } \\
(N=102)\end{array}$ & $\begin{array}{c}\text { Group II } \\
(N=269)\end{array}$ & $\begin{array}{c}\text { Mann-Whitney } \\
\boldsymbol{U} \text { test } \\
\text { Value of } \boldsymbol{p}\end{array}$ \\
\hline MCA: & $65 \pm 15$ & $71 \pm 20$ & 0.015 \\
\hline PSV & $31 \pm 8$ & $31 \pm 12$ & 0.761 \\
\hline EDV & $71 \pm 24$ & $86 \pm 34$ & $<0.001$ \\
\hline ACA: & $32 \pm 12$ & $37 \pm 17$ & 0.038 \\
\hline PSV & & & 0.431 \\
\hline EDV & $60 \pm 18$ & $63 \pm 23$ & 0.554 \\
\hline PCA: & $27 \pm 12$ & $27 \pm 11$ & \\
\hline PSV & & & \\
\hline EDV & & & \\
\hline
\end{tabular}

*Value of $p$ is given for PSV. concomitant diseases, except for past history of myocardial infarction. Clinical characteristics of study groups are presented in Table I.

Mean grade of ICAS was $85 \pm 9.6 \%$ (range: $70-100 \%$ ) in group I and $83 \pm 9.4 \%$ (range: $70-100 \%$ ) in group II, and did not differ significantly between the study groups $(p=0.089)$.

Group I patients had lower mean PSV in the MCA and ACA as compared to group $\|(65 \pm 15 \mathrm{~cm} / \mathrm{s}$ vs. 71 $\pm 20 \mathrm{~cm} / \mathrm{s}, p=0.015$ and $71 \pm 24 \mathrm{~cm} / \mathrm{s}$ vs. $86 \pm 34 \mathrm{~cm} / \mathrm{s}$, $p<0.001$, respectively), as well as lower EDV in ACA $(32 \mathrm{~cm} / \mathrm{s}$ vs. $37 \mathrm{~cm} / \mathrm{s}, p=0.038)$. No significant differences between the respective groups in MCA EDV $(31 \pm 8 \mathrm{~cm} / \mathrm{s}$ vs. $31 \pm 12 \mathrm{~cm} / \mathrm{s}, p=0.761)$, PCA PSV and EDV $(p=0.431$ and $p=0.554$, respectively) were observed. The mean values of PSV as well as EDV measured in group I and group II in the ipsilateral MCA, ACA and PCA are given in Table II.

In group I, 55 out of 102 (54\%) patients had cerebral collateral flow through the ACOA, which resulted in flow reversal in segment 1 of the ACA, e.g. the same flow direction as in the MCA on the side of the ICAS. Meanwhile, in group II, collateral circulation via the ACoA was observed in 211 out of $269(78 \%)$ patients $(p<0.001)$. The frequency of functional collateral cerebral circulation is shown in Table III.

Twenty (20\%) patients from group I and $113(42 \%)$ from group II had at least one PCoA present $(p<0.001)$, which allowed antegrade flow from the P1/P2 segment of the PCA to the trifurcation of the ICA and then on to the MCA and ACA.

Likewise, there was also a significant difference in presence of any collateral cerebral circulation, through either ACOA or PCoA. The collateral blood flow was present

Table III. Frequency of functional collateral circulation through ACoA or PCoA or both in neurologically symptomatic patients (group I) vs. asymptomatic patients (group II)

\begin{tabular}{lccc} 
Variable & $\begin{array}{c}\text { Group I } \\
(N=102)\end{array}$ & $\begin{array}{c}\text { Group II } \\
(N=269)\end{array}$ & $\begin{array}{c}\chi^{2} \\
\text { Value of } p\end{array}$ \\
\hline ACoA: & $55(54 \%)$ & $211(78 \%)$ & $<0.001$ \\
\hline Present & $47(46 \%)$ & $58(22 \%)$ & \\
\hline Absent & & & \\
\hline PCoA: & $20(20 \%)$ & $113(42 \%)$ & $<0.001$ \\
\hline Present & $82(80 \%)$ & $156(58 \%)$ & \\
\hline Absent & & & \\
\hline ACoA and/or PCoA: & $68(67 \%)$ & $231(86 \%)$ & $<0.001$ \\
\hline Present & $34(33 \%)$ & $38(14 \%)$ & \\
\hline Absent &
\end{tabular}


in 68 (67\%) patients in group I, and in $231(86 \%)$ patients in group II $(p<0.001)$.

Analyzing group II patients, a functional ACoA was present in 77 out of 93 (83\%) asymptomatic patients and in 134 out of 176 (76\%) with previous IS older than 3 months $(p=0.207)$, while a PCoA was present in $32(34 \%)$ and $80(46 \%)(p=0.074)$, and overall any crossflow was present in $82(88 \%)$ and $148(84 \%)$ of respective subjects $(p=0.366)$.

The differences between ACOA and PCoA presence were statistically significant between patients with recent IS as compared to remote IS ( $p<0.001$ for ACoA, $p<0.001$ for PCOA, and for any cross-flow $p<0.001$ ), which suggests development of collaterals with time passed since IS.

In order to evaluate the important risk factors for occurrence of IS in patients with severe ICAS, binominal backward stepwise logistic regression was used. Variables from the univariate analysis with $p$-value $<0.100$ entered the model. Eventually, the predictors taken into analysis were: presence of ACoA, presence of PCoA, PSV in MCA, PSV in ACA, EDV in ACA and history of previous myocardial infarction. The model was statistically significant $(p<0.001)$. Presence of ACOA and PCoA reduced the risk of symptomatic ICAS by $72 \%(R R=0.28,95 \% \mathrm{Cl}=$ $0.16-0.49)$ and $72 \%(R R=0.28, C l: 0.15-0.52)$, respectively $(p<0.001)$. The increase of PSV in the MCA or ACA by $1 \mathrm{~cm} / \mathrm{s}$ contributed to IS occurrence risk reduction by $3 \%(\mathrm{RR}=0.97,95 \% \mathrm{Cl}=0.96-0.99, p<0.001)$ and $1 \%$ $(\mathrm{RR}=0.99,95 \% \mathrm{Cl}=0.98-0.99, p=0.032)$, respectively.

A

ROC curve

Cut-off PSV in MCA $76.00 \mathrm{~cm} / \mathrm{s}$ $\mathrm{AUC}=0.582,95 \% \mathrm{Cl}: 0.52-0.644, p=0.0094$ Sensitivity $84.3 \%$, specificity $33.8 \%$

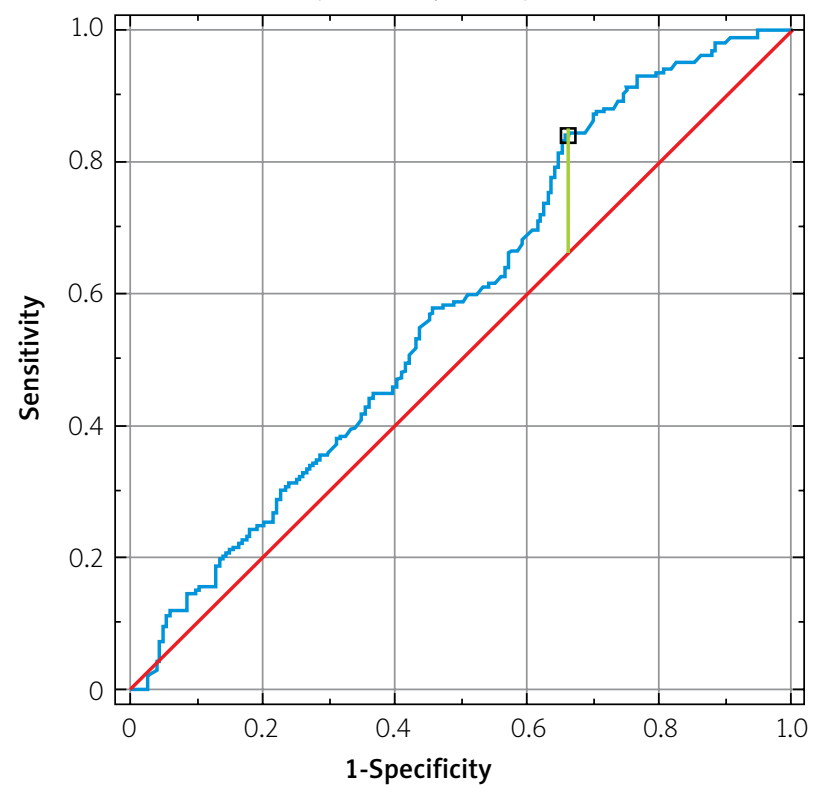

Interestingly, the history of myocardial infarction reduced the risk of IS by $63 \%(R R=0.37,95 \% \mathrm{Cl}=0.20-0.70$, $p=0.002$ ). Independent predictors of IS are shown in Table IV.

Finally, a ROC analysis was performed to determine the best PSV cut-off values in the MCA or ACA for estimation of the risk of IS. The ROC curves showed that there were no good PSV cut-off values for either the MCA (AUC $=0.582)$ or the ACA (AUC $=0.642)$ (Figures $1 \mathrm{~A}, \mathrm{~B})$. The PSV in the MCA below $76 \mathrm{~cm} / \mathrm{s}$ and PSV in the ACA $<70 \mathrm{~cm} / \mathrm{s}$ were characterized by a sensitivity and specificity of $84 \%$ and $34 \%$ for MCA and $60 \%$ and $67 \%$ for ACA, respectively.

\section{Discussion}

The TCCD sonography and phase-contrast magnetic resonance angiography (MRA) are widely used to determine cross flows through the ACOA and PCOA because these techniques can detect anatomy and flow directions

Table IV. Independent predictors of ischemic stroke

\begin{tabular}{lcc} 
Variable & RR $(95 \% \mathrm{CI})$ & Value of $p$ \\
\hline Presence of ACoA & $0.28(0.16-0.49)$ & $<0.001$ \\
\hline Presence of PCoA & $0.28(0.15-0.52)$ & $<0.001$ \\
\hline MCA, PSV & $0.97(0.96-0.99)$ & $<0.001$ \\
\hline ACA, PSV & $0.99(0.98-0.99)$ & 0.032 \\
\hline Previous myocardial infarction & $0.37(0.20-0.70)$ & 0.002
\end{tabular}

B ROC curve Cut-off PSV in ACA $70.00 \mathrm{~cm} / \mathrm{s}$ $\mathrm{AUC}=0.642,95 \% \mathrm{Cl}: 0.579-0.704, p<0.001$ Sensitivity $60.6 \%$, specificity $66.9 \%$

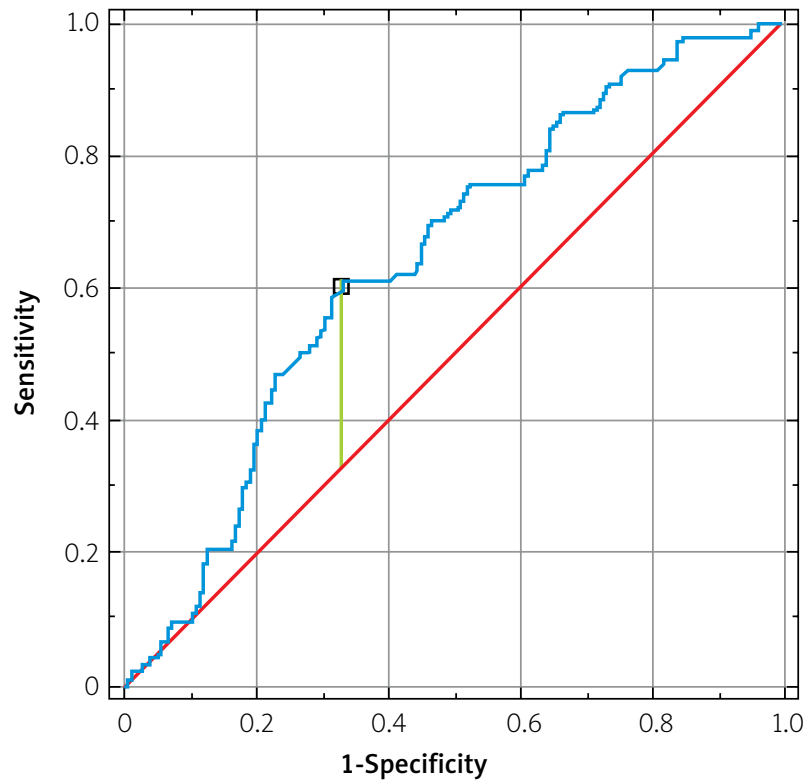

Figure 1. Receiver-operator characteristic (ROC) curves showed no good cut-off values for PSV in MCA or ACA to discriminate increased risk of IS 
in the circle of Willis. Both studies, TCCD and dynamic MRA, have similar power for detection of cerebral collaterals $[9,10]$.

The major finding of the present study is that patients with severe ICAS and recent IS have low prevalence of functional collateral cerebral circulation. We evidenced presence of the ACOA in 54\% and of the PCoA in $20 \%$ of patients with recent IS, as compared to $78 \%$ and $42 \%$ in asymptomatic ones, respectively. Similarly, in the small preliminary study by to et al., involving 12 subjects, presence of the ACOA and PCOA on dynamic MRA was observed in $42 \%$ and $17 \%$ of symptomatic patients with ICAS > 70\%, respectively [11]. Also, autopsy studies revealed that patients who had died of IS resulting from severe ICAS more often had hypoplasia of the ACOA [12-14].

However, Hendrikse et al. found no significant differences in $\mathrm{ACOA}$ and $\mathrm{PCOA}$ prevalence, with the $\mathrm{ACOA}$ accounting for $63 \%$ out of 35 subjects with IS within the last 6 months vs $69 \%$ out of 16 asymptomatic subjects ( $p=0.683)$, and the PCoA in $31 \%$ vs. $31 \%(p=0.989)$, respectively [15]. Our observations indicated that the cross-flow can develop with time passed since IS, accounting for ACOA and PCOA presence in $54 \%$ and $20 \%$ of patients respectively with recent IS, as compared to $76 \%$ and $46 \%$ of subjects with IS later than 3 months. However, it is worth mentioning that after 3 months following IS, the prevalence of cross-flows between asymptomatic and symptomatic subjects does not differ significantly.

To our knowledge, large scale studies have not been conducted, while the issue of collateral flow development in patients with severe ICAS seems to play a key role in developing symptoms of cerebral ischemia.

The second major finding of the present study is to prove that the lack of cross flow is an independent risk factor of IS. We have evidenced the protective role of collaterals, interestingly similar for both ACOA and PCOA. Presence of an ACoA is associated with a $72 \%$ risk reduction of IS. The fact of ACoA presence is even more important than PSV in the MCA and ACA. Although lower PSVs in the MCA and ACA are related to higher risk of IS, the ROC curves failed to indicate cut-off values for PSV in the MCA and ACA that could reliably determine the risk increase of IS. The PSV cut-offs in the MCA $(<76 \mathrm{~cm} / \mathrm{s})$ and ACA $(<70 \mathrm{~cm} / \mathrm{s})$ revealed only a moderate association with IS risk.

This should be discussed in the context of an experimental model of cerebral circulation in the study of Cassot et al., in which different efficiency of cross-flow was evidenced depending on the ACOA diameter. The ACOA behaved like an occluded vessel when its diameter was $<0.4 \mathrm{~mm}$. In contrast, the ACOA was fully functional if its diameter exceeded $1.6 \mathrm{~mm}$, providing long-term autoregulation of cerebral flow in the MCA on the side of the ICAS $[16,17]$. Within the range of $0.4-1.6 \mathrm{~mm}$ even small changes in ACoA diameter significantly impacted the he- modynamics of cerebral circulation. In our study, presence of a PCOA was associated with lower risk of IS, which is in line with the observations of other authors [18, 19].

Assuming that the ACoA plays an important role in preventing IS associated with the hypoperfusion mechanism, it is still open to discussion what minimal flow volume is required $[15,20]$. This could probably be answered by MRA and MRI perfusion studies with the assessment of cerebral perfusion defect as well as cerebral flow volumes [21, 22]. In the study by Zareie et al., in a group of 90 consecutive subjects admitted with acute IS (less than $6 \mathrm{~h}$ from symptoms onset), the ACoA was present in $45 \%$ of subjects and it was independently related to a lesser degree of cerebral perfusion defect, e.g. smaller infarct volume at 2 time points - on admission and after $24 \mathrm{~h}$ of hospital stay [21].

Furthermore, our study showed that the degree of ICA stenosis is a less important discriminator for hemodynamic impairment than the collateral status of the cerebral circulation.

The other major issue is whether collateral flow can develop with time passed after IS resulting from ICAS, or whether cerebral ischemia may be prompted by the incomplete circle of Willis, e.g. one or more collaterals are missing [23-25]. In the first case, patients with recent IS would be at high, but decreasing risk of recurrent IS until the collateral pathways are well developed. In the second case, absent cross flows expose the patient to the permanent risk of IS recurrence due to steady cerebral inflow limitation. Anyway, the first and the later condition should result in careful patient assessment for carotid revascularization in view of secondary IS prevention, optimally as quickly as possible [26].

Clinical data indicate that the risk of IS is greater in the first month following the cerebral ischemic event. This may indicate that decreasing risk may be related to the gradual development of cerebral cross-flow. It seems reasonable that patients after IS, with low PSV in the MCA, should be considered as candidates for urgent carotid artery revascularization [27].

It is still open to speculation whether stroke may have been caused by distal embolization of the cerebral artery or the quality of the flow within the ACoA was not sufficient to maintain MCA flow at an adequate level.

\section{Conclusions}

The ACOA and the PCOA are more frequently present in asymptomatic patients with severe ICAS, as compared to patients with recent IS with severe ICAS. The presence of cross-flows and PSVs in the MCA and ACA were found to be independent predictors of IS risk, more important than ICAS degree alone. Despite IS, in some proportion of patients, a cross-flow probably reduces the risk of a recurrent cerebral event. 


\section{Conflict of interest}

The authors declare no conflict of interest.

\section{References}

1. Al-Mubarak N, Roubin GS, Liu MW, et al. Early results of percutaneous intervention for severe coexisting carotid and coronary artery disease. JACC 1999; 84: 600-2.

2. Satiani B, Porter RM Jr, Biggers KM, et al. Natural history of nonoperated, significant carotid stenosis. Ann Vasc Surg 1988; 2: 271-8.

3. Rothwell PM, Slattery J, Warlow CP. Clinical and angiographic predictors of stroke and death from carotid endarterectomy: systematic review. BMJ 1997; 315: 1571-77.

4. Pedro LM, Fernandes J, Pedro MM, et al. Ultrasonographic risk score of carotid plaques. Eur J Vasc Endovasc Surg 2002; 24: 492-8.

5. Mathiesen EB, Bonaa KH, Joakimsen O. Echolucent plaques are associated with high risk of ischemic cerebrovascular events in carotid stenosis: the Tomso study. Circulation 2001; 103: 2171-5.

6. Kabłak-Ziembicka A, Przewłocki T, Pieniążek P, et al. Evaluation of cerebral circulation in patients with significant carotid artery stenosis. Kardiol Pol 2005; 63: 381-9.

7. North American Symptomatic Carotid Endarterectomy Trial Collaborators. Beneficial effect of carotid endarterectomy in symptomatic patients with high-grade carotid stenosis. N Engl J Med 1991; 325: 445-53.

8. Carpenter JP, Lexa FJ, Davis JT. Determination of duplex Doppler ultrasound criteria appropriate to the North American Symptomatic Carotid Endarterectomy Trial. Stroke 1996; 27: 695-9.

9. Sallustio F, Kern R, Günther M, et al. Assessment of intracranial collateral flow by using dynamic arterial spin labeling MRA and transcranial color-coded duplex ultrasound. Stroke 2008; 39: 1894-7.

10. Hendrikse J, Klijn CJ, van Huffelen AC, et al. Diagnosing cerebral collateral flow patterns: accuracy of non-invasive testing. Cerebrovasc Dis 2008; 25: 430-7.

11. Ito K, Sasaki M, Kobayashi M, et al. Noninvasive evaluation of collateral blood flow through circle of Willis in cervical carotid stenosis using selective magnetic resonance angiography. J Stroke Cerebrovasc Dis 2014; 23: 1019-23.

12. Kamath S. Observations on the length and diameter of vessels forming the circle of Willis. J Anat 1981; 133: 419-23.

13. Hillen B. The variability of the circle of Willis: univariate and bivariate analysis. Acta Morphol Neerl Scand 1986; 24: 87-101.

14. Fisher CM. The Circle of Willis: anatomical variations. Vasc Dis 1965; 2: 99-105.

15. Hendrikse J, Hartkamp M, Hillen B, et al. Collateral ability of the circle of Willis in patients with unilateral internal carotid artery occlusion. Stroke 2001; 32: 2768-73.

16. Cassot F, Vergeur V, Bossuet P, et al. Effects of anterior communicating artery diameter on cerebral hemodynamics in internal carotid artery disease. Circulation 1995; 92: 3122-31.

17. Hoksbergen AW, Legemate DA, Ubbink DT, Jacobs NJ. Collateral variations in circle of Willis in atherosclerotic population assessed by means of transcranial color-coded duplex ultrasonography. Stroke 2000; 31: 1656-60.

18. Klotzsch C, Popescu O, Berlit P. Assessment of the posterior communicating artery by transcranial color-coded duplex sonography. Stroke 1996; 27: 486-9.
19. Shomer DF, Marks MP, Steinberg GK, et al. The anatomy of the posterior communicating artery as a risk factor for ischemic cerebral infarction. N Engl J Med 1994; 330: 1565-70.

20. Reinhard M, Muller T, Guschlbauer B, et al. Dynamic cerebral autoregulation and collateral flow patterns in patients with severe carotid stenosis or occlusion. Ultrasound Med Biol 2003; 29: 1105-13.

21. Zareie $\mathrm{H}$, Quain DA, Parsons $\mathrm{M}$, et al. The influence of anterior cerebral artery flow diversion measured by transcranial Doppler on acute infarct volume and clinical outcome in anterior circulation stroke. Int J Stroke 2013; 8: 228-34.

22. Beretta S, Cuccione E, Versace A, et al. Cerebral collateral flow defines topography and evolution of molecular penumbra in experimental ischemic stroke. Neurobiol Dis 2015; 74: 305-13.

23. Baumgartner RW. Transcranial color duplex sonography in cerebrovascular disease: a systematic review. Cerebrovasc Dis 2003; 16: 4-13.

24. Krabbe-Hartkamp MJ, van der Grond J, de Leeuw FE, et al. Circle of Willis: morphologic on three-dimensional time-of-flight MR-angiograms. Radiology 1998; 207: 103-11.

25. Hoksbergen AW, Fulesdi B, Legemate DA, et al. Collateral configuration of the circle of Willis. Transcranial color-coded duplex ultrasonography and comparison with postmortem anatomy. Stroke 2000; 31: 1346-51.

26. Pieniazek P, Musialek P, Kablak-Ziembicka A, et al. Carotid artery stenting with patient- and lesion-tailored selection of the neuroprotection system and stent type: early and 5 -year results from a prospective academic registry of 535 consecutive procedures (TARGET-CAS). J Endovasc Ther 2008; 15: 249-62.

27. Kosowski M, Zimoch W, Gwizdek T, et Al. Safety and efficacy assessment of carotid artery stenting in a high-risk population in a single-centre registry. Postep Kardiol Inter 2014; 10: 258-63. 